\title{
Associated Cutaneous Diseases in Obese Adult Patients: A Prospective Study from a Skin Referral Care Center
}

\author{
Nawaf Al-Mutairi \\ Department of Medicine, Faculty of Medicine, Health Sciences Centre, Kuwait University, Jabriya, Kuwait
}

\author{
Key Words \\ Obesity · Acanthosis nigricans · Acrochordon · Diabetes \\ mellitus
}

\begin{abstract}
Objective: The aim of the present study was to determine the spectrum of skin diseases seen among adult obese patients referred to Farwaniya Hospital. Materials and Methods: A total of 437 overweight/obese subjects (200 men and 237 women) aged 18-74 years were enrolled in the study, which was conducted from October 2008 to November 2009. Demographic details such as age, sex, occupation, personal and family history of diabetes mellitus, hypertension, and obesity were recorded. A thorough examination was performed by an experienced dermatologist (N.A.M.). Blood investigations such as complete blood count, fasting and postprandial blood sugar levels, liver function tests, kidney function tests, lipid profile, and thyroid function tests were done for all patients in addition to hormonal assay and abdominal sonar to exclude polycystic ovary disease for indicated patients. Results: Common skin diseases found among these patients were plantar hyperkeratosis: $n=197$; acanthosis nigricans: $\mathrm{n}=144$; skin tags: $\mathrm{n}=131$; striae cutis distensae: $\mathrm{n}=102$; intertrigo: $\mathrm{n}=97$; acne vulgaris: $\mathrm{n}=94$. Diabetes mellitus was diagnosed in 87 patients, polycystic ovary syndrome/hyperandrogenism in 74 female patients, and hyperlipidemia in 209 patients. Conclusion: This study shows that
\end{abstract}

certain dermatoses such as plantar hyperkeratosis, acanthosis nigricans, skin tags, striae cutis distensae, and intertrigo are more common among obese persons. Some, such as plantar hyperkeratosis, could serve as markers of obesity and its severity, while the presence of acanthosis nigricans and skin tags may point to underlying internal disease such as diabetes and polycystic ovary syndrome.

Copyright $\odot 2011$ S. Karger AG, Basel

\section{Introduction}

Obesity is defined as a pathologic state of excess adipose tissue for the size of the body. Body mass index (BMI) is a statistical measure commonly used in classifying overweight and obesity within a population calculated by dividing the weight in kilograms by the square of the height in meters $\left(\mathrm{kg} / \mathrm{m}^{2}\right)$. The World Health Organization defines 'overweight' as a BMI $\geq 25 \mathrm{~kg} / \mathrm{m}^{2}$, and 'obesity' as a BMI $\geq 30 \mathrm{~kg} / \mathrm{m}^{2}$. In 2005, the World Health Organization estimated that worldwide approximately 1.6 billion adults (age $\geq 15$ years) were overweight. Over 400 million adults (approximately 7\%) suffer from obesity [1], and at least 20 million children under the age of 5 years are overweight. Once considered a problem only in high-income countries, overweight and obesity are now dramatically on the rise in low- and middle-income countries, particularly in urban settings [1].

\section{KARGER \\ Fax +4161306 1234 \\ E-Mail karger@karger.ch}

www.karger.com
(C) 2011 S. Karger AG, Basel

1011-7571/11/0203-0248\$38.00/0

Accessible online at:

www.karger.com/mpp
Dr. Nawaf Al-Mutair

PO Box 280

80000 Farwaniya (Kuwait)

Tel. +9659937 0203, Fax +965 24808167

E-Mailnalmut@usa.net 
A number of chronic as well as acute life-threatening systemic diseases are related to obesity [2]. They include conditions such as coronary heart disease, hypertension, diabetes, hyperlipidemia, osteoarthritis, sleep apnea, breast, endometrial and colon carcinoma, gallbladder disease, and severe pancreatitis [3]. The role of obesity in these conditions is well documented and reported, however, there is a scarcity of studies on skin diseases encountered among obese people from different countries [4-6].

Obesity affects skin physiology by altering skin barrier function, sebum production, sweat gland function, lymphatics, collagen structure, wound healing, subcutaneous fat, microcirculation, and macrocirculation [7]. It has been implicated in many skin diseases such as acanthosis nigricans, acrochordon, keratosis pilaris, hyperandrogenism, hirsutism, striae cutis distensae, adiposis dolorosa, fat redistribution, lymphedema, plantar hyperkeratosis, cellulite, skin infections, hidradenitis suppurativa, psoriasis, and insulin resistance syndrome and conditions that are aggravated by obesity $[8,9]$. Several studies have shown that there is a high prevalence of obesity in Kuwait $[10,11]$.

Since the discovery of oil and its export, the enhanced affluence has brought about a sedentary lifestyle and high consumption of calorie-rich food, resulting in Kuwaitis having one of the highest prevalences of obesity among the Gulf countries [12]. In fact, a policy paper even reported that Kuwait has the highest prevalence of obesity in the entire world [12].

No study has been conducted to determine the prevalence and spectrum of skin diseases among obese $\mathrm{Ku}$ waitis, which prompted me to conduct this study to determine the spectrum of skin conditions and related systemic conditions, and estimate their prevalence among obese adult Kuwaitis attending the dermatology outpatient clinic of Farwaniya Hospital, Kuwait.

\section{Materials and Methods}

This study was conducted in the Dermatology Department of Farwaniya Hospital, a secondary care hospital serving a population of approximately 820,300 persons in Kuwait. It was carried out over a period of 1 year, from October 2008 to November 2009. One thousand two hundred and fifty new adult patients $>18$ years of age with a BMI over $25 \mathrm{~kg} / \mathrm{m}^{2}$ referred from primary care physicians and other specialties to the Dermatology OPD for dermatological problems were asked to enroll in the study. An informed consent was taken from every patient and the study was approved by the Ethics Committee of the hospital. Demographic and clinical data such as age, sex, occupation, personal and family history of diabetes, hypertension, and obesity was recorded. A thorough general physical, systemic and cutaneous examination was per- formed on each patient by an experienced dermatologist. Blood investigations such as complete blood count, fasting and postprandial blood sugar levels, liver, kidney and thyroid function tests, and serum lipid profile were done for each patient. Serum $\mathrm{FH}, \mathrm{LSH}$ and prolactin levels and pelvic ultrasound were performed for $69(15 \%)$ female patients with hirsutism, alone or in the presence of acanthosis nigricans and/or acne.

The height of each participant was measured to the last $0.1 \mathrm{~cm}$ by having him/her stand erect with his/her back against a wall and marking the point of the top of his/her head without wearing shoes. Weight was recorded to the last $100 \mathrm{~g}$ with a mechanical balance device. Participants were asked to remove their shoes and outer garments if they wore extra layers. BMI calculated as weight in kilograms divided by height in meters squared $\left(\mathrm{kg} / \mathrm{m}^{2}\right)$ was used as the index of adiposity. Patients were categorized into three grades: grade 1 , overweight $(\mathrm{BMI}>25-30)$; grade 2 , obese (BMI $>30-40)$, and grade 3, morbidly/severely obese (BMI $>40$ ).

Data collected was analyzed using the Statistical Products of Service Solutions (SPSS) version 10 . The $\chi^{2}$-test was performed.

\section{Results}

A total of 437 (200 men and 237 women) overweight or obese patients who consented to participate were included in this cross-sectional study. All participants were aged 18-74 years living in the Farwaniya governorate in the central region of Kuwait.

The mean BMI and prevalence of obesity by age and gender are given in table 1. Of the 437 patients, 191 (43.7\%, male: 95 and female: 96) were overweight (grade 1); 226 (51.7\%, male: 97; female: 129) were obese (group 2), and 20 (4.65\%, male: 8 and female: 12$)$ were severely obese (grade 3). The highest incidence (31.8\%) was among the age group 30-39 years followed by $40-49$ years.

The spectrum and prevalence of skin conditions discovered among these obese patients is given in table 2 . Skin diseases were as follows: plantar hyperkeratosis: 197 patients; acanthosis nigricans: 144; skin tags: 131; striae cutis distensae: 102; intertrigo: 97, and acne vulgaris: 94 . Many patients had more than two conditions. The most frequent combination observed was acanthosis nigricans with acne, acanthosis nigricans with acne and hirsutism, plantar hyperkeratosis with intertrigo.

The number of obese patients with comorbidities associated with their dermatological problems is shown in figure 1. Eighty-seven patients were diabetic (38 already diagnosed; 49 cases of diabetes mellitus detected during the study). Of the 87 diabetic patients, 39 had both skin tags and acanthosis nigricans, 15 skin tags alone; 33 had intertrigo, 12 had acanthosis nigricans and acne. Polycystic ovary syndrome/hyperandrogenism was diagnosed in 74 female patients: 35 with hirsutism, 22 with acanthosis 
Table 1. Distribution of overweight and obesity by age and gender attending a dermatology clinic in a large public hospital in Kuwait

\begin{tabular}{|c|c|c|c|c|c|c|c|c|c|}
\hline \multirow{2}{*}{$\begin{array}{l}\text { Age } \\
\text { group }\end{array}$} & \multicolumn{6}{|c|}{ Obesity } & \multirow{2}{*}{\multicolumn{2}{|c|}{ Total $(\mathrm{n}=437)$}} & \multirow{2}{*}{$\begin{array}{l}\text { Overall } \\
\%\end{array}$} \\
\hline & \multicolumn{2}{|c|}{ grade $1(n=191)$} & \multicolumn{2}{|c|}{ grade $2(n=226)$} & \multicolumn{2}{|c|}{ grade $3(n=20)$} & & & \\
\hline $20-29$ & 18 & 23 & 17 & 28 & 0 & 0 & 35 & 51 & 19.68 \\
\hline $30-39$ & 31 & 32 & 31 & 44 & 1 & 0 & 63 & 76 & 31.81 \\
\hline$\geq 60$ & 8 & 5 & 12 & 18 & 2 & 4 & 22 & 27 & 11.21 \\
\hline Total & 95 & 96 & 97 & 129 & 8 & 12 & 200 & 237 & 100 \\
\hline
\end{tabular}

Table 2. Distribution of some common skin diseases according to age, sex and obesity grade

\begin{tabular}{|c|c|c|c|c|c|c|c|c|c|}
\hline \multirow[t]{2}{*}{ Disease group } & \multicolumn{6}{|c|}{ Obesity } & \multirow[t]{2}{*}{ Total } & \multirow[t]{2}{*}{$\%$} & \multirow{2}{*}{$\begin{array}{l}\chi^{2} \\
\text { ( } p \text { value })\end{array}$} \\
\hline & \multicolumn{2}{|c|}{ grade 1} & \multicolumn{2}{|c|}{ grade 2} & \multicolumn{2}{|c|}{ grade 3} & & & \\
\hline Plantar hyperkeratosis & 39 & 43 & 46 & 49 & 8 & 12 & 197 & 45.1 & \\
\hline Acanthosis nigricans & 21 & 39 & 35 & 38 & 3 & 8 & 144 & 33.0 & \\
\hline Intertrigo & 19 & 25 & 17 & 26 & 7 & 3 & 97 & 22.2 & 44.75 \\
\hline Acne vulgaris & 13 & 17 & 31 & 22 & 6 & 5 & 94 & 21.5 & $(0.004)$ \\
\hline Hirsutism & 0 & 19 & 0 & 41 & 0 & 9 & 69 & 15.8 & \\
\hline Folliculitis & 4 & 15 & 12 & 17 & 0 & 1 & 49 & 11.2 & \\
\hline Tinea cruris & 10 & 3 & 17 & 11 & 1 & 0 & 42 & 9.6 & \\
\hline Hyperhidrosis & 12 & 5 & 14 & 6 & 0 & 0 & 37 & 8.5 & \\
\hline
\end{tabular}

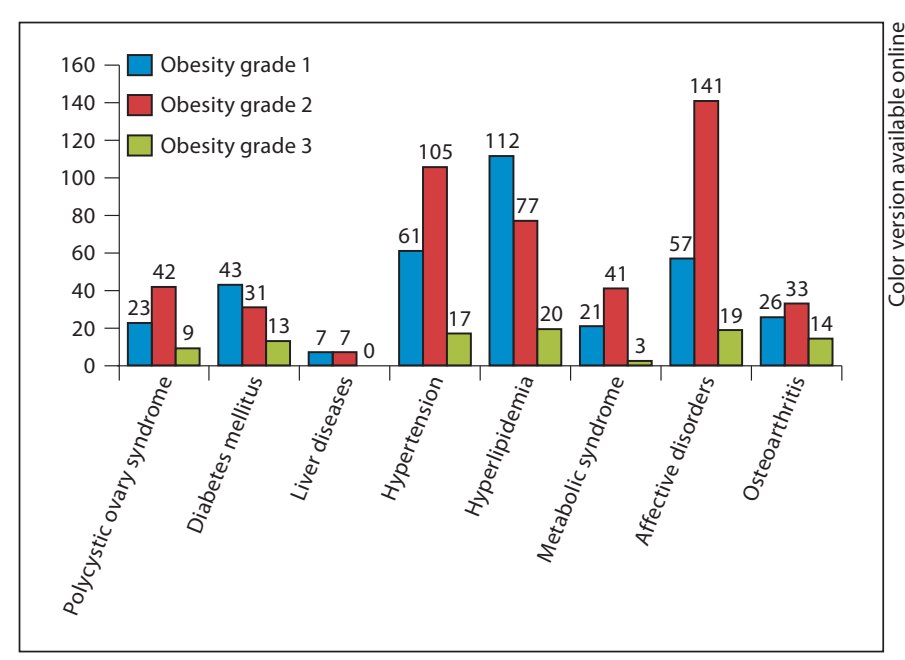

Fig. 1. Prevalence of various comorbidities associated with obesity according to grades of severity of obesity. nigricans and hirsutism, 12 with acanthosis nigricans, hirsutism and severe acne. Two hundred and nine patients were found to have hyperlipidemia.

\section{Discussion}

The common findings of plantar hyperkeratosis, acanthosis nigricans, skin tags, striae cutis distensae, intertrigo, acne vulgaris and hirsutism associated with obesity of this study are similar to those reported by Garcia et al. [4]. Plantar hyperkeratosis, the most common skin condition found in our study, has been described as a cutaneous stigma of severe obesity [4]. The prevalence of plantar hyperkeratosis of this study is comparable to the $47 \%$ reported by Sharquie et al. [5]. Development of plantar hyperkeratosis may be regarded as a physiologic response to 
mechanical trauma, as obese patients have increased forefoot width and higher plantar pressures during walking and standing [13].

Acanthosis nigricans is a consistently reported finding in studies of obese persons $[6,14]$ and it is the most common dermatological condition associated with obesity reported in the literature. However, the prevalence of acanthosis nigricans in this study is lower than the 74\% [6] and $76 \%$ [14] reported for the USA and Brazil, respectively, but higher than the $0.6 \%$ [15] for Egypt. In addition, Hud et al. [6] reported that obese patients exhibited acanthosis nigricans with elevated plasma insulin levels. Acanthosis nigricans is now considered a reliable cutaneous marker of hyperinsulinemia in obese individuals [6]. In obese patients, acanthosis nigricans may be the result of the inappropriate, simultaneous activation of distinct tyrosine kinase growth factor receptors due to excessive levels of circulating insulin [16]. Hyperinsulinemia increases the production of ovarian androgens, which may lead to associated hirsutism and acne vulgaris. The clinical triad of polycystic ovaries, hirsutism, and acanthosis nigricans is commonly observed in obese females [17].

It was shown that leptin could play a paracrine role in the cell proliferation, differentiation, growth, and apoptosis of epithelial cells [18]. Yazici et al. [19] speculated that acanthosis nigricans in their patient was related to the high level of leptin.

Full regression of acanthosis nigricans may occur with weight loss as reported by Katz et al. [20], who noticed rapid improvement in the acanthosis nigricans once the patient started to lose weight. Hence, they concluded that the most effective treatment of acanthosis nigricans is weight loss and exercise if the lesions are caused by hyperinsulinemia.

Skin tags (acrochorda) were present in $30.0 \%$ of patients, which is less than the $74 \%$ reported by Hud et al. [6] that was positively correlated with the severity of obesity as was also reported by Garcia et al. [4]. A subset of patients was found to have mean fasting insulin levels twice that of the patients without skin lesions [6]. Multiple skin tags are frequently associated with non-insulindependent diabetes mellitus and obesity [21]. However, Rasi et al. [22] in a case-control study suggested that skin tags could be a more valuable marker of carbohydrate intolerance and diabetes mellitus than obesity.

The prevalence of $21.5 \%$ for acne in this study was much higher than $6.8 \%$ that was reported in obese adults in Egypt [15]. Acne is clearly exacerbated by obesity-associated disorders, such as hyperandrogenism and hirsutism. Androgens, insulin, growth hormone, and insulin- like growth factors are frequently elevated in obese patients and have been demonstrated to activate sebaceous glands and influence acne severity. Adipose tissue synthesizes testosterone, and the hyperinsulinemia commonly seen with obesity increases the production of ovarian androgens. Testosterone primarily binds to albumin and sex hormone-binding globulin. Because insulin inhibits the synthesis of sex hormone-binding globulins, the free testosterone in a woman's serum is increased. This increase in testosterone may lead to male-patterned baldness, hirsutism and acne in obese women.

Striae cutis distensae (stretch marks) correlate closely with obesity. The prevalence of $23.3 \%$ confirmed those reported by Garcia et al. [4] and Sharquie et al. [5], but was much higher than the $0.8 \%$ reported in adult Egyptians [15].

Intertrigo was prevalent in $22.2 \%$ of the patients of this study and this was lower than the 52\% reported among obese people in neighboring Iraq [5]. There is a linear trend between the severity of obesity and intertrigo [4]. In a study evaluating intertrigo in diabetic patients, skin surface $\mathrm{pH}$ was found to be higher in the inguinal folds of women with a BMI greater than 25 compared with women with a BMI less than 25 [23].

Hirsutism was diagnosed in $15.8 \%$ of obese female patients. Ruutiainen et al. [24] found that facial hirsutism is significantly correlated with BMI independently of age and testosterone level. Hirsutism is considered the primary clinical indicator of androgen excess. After oligomenorrhea, hirsutism is the second most common manifestation of polycystic ovary syndrome. Seventy-four of the obese patients were diagnosed as having polycystic ovary syndrome, 69 of them were hirsute, 43 also had acne, and 26 had acanthosis nigricans.

Twenty-eight (6.4\%) patients had psoriasis in this study; 12 of them were overweight (grade 1 obesity) and 16 were obese (grade 2 obesity). No patient with grade 3 obesity was diagnosed as having psoriasis. There were 20/28 psoriatic obese patients who were females. There was no relation between the degree of obesity and the severity of psoriasis; however, obesity has been linked to psoriasis as a comorbid state with significant impact on psoriasis management $[25,26]$. In a 10 -year study, Sakai et al. [25] showed that elevated BMI $(>25)$ was significantly associated with long-term prognosis of psoriasis while Naldi et al. [26] reported that clinical obesity (BMI $>29$ ) more than doubled the risk of psoriasis. Johnston et al. [27] concluded that increased adiposity is associated with raised levels of circulating cytokines, including leptin and resistin, which may promote activation of 
T cells and monocytes, driving both Th1 and Th17 immune responses and at the same time impairing the function of regulatory T cells. Diet also appears to have a significant influence on psoriasis. However, more prospective studies are needed to determine whether weight control reduces psoriasis morbidity.

\section{Limitations of the Study}

The number of subjects consenting to participate in the study was very low at about one third, amongst the 1,250 patients seen during the same period.

\section{Conclusion}

The current study has shown that certain skin conditions are more prevalent among obese persons. In particular, there is a high incidence of plantar hyperkeratosis, acanthosis nigricans, skin tags, striae cutis distensae, and intertrigo. Similarly, skin tags can point toward noninsulin-dependent diabetes mellitus. Although dermatologists may be the first to be consulted by patients having these common dermatoses and may play an important role in the management and early detection of underlying systemic conditions, if present, all physicians should be aware of this. Dermatologists must work with primary care physicians and nutritional specialists to reduce the detrimental effects of obesity on the skin. More clinicoepidemiological studies are needed to establish the association of obesity with some of these conditions.

\section{Acknowledgments}

I would like to thank Dr. Mazen Al-Sheltawi and Dr. Osama Nour-Eldin from the Dermatology Department, Farwaniya Hospital for their technical help. I also thank all patients who kindly participated in the study.

\section{References}

1 Obesity and overweight: http://www.who. int/mediacentre/factsheets/fs311/en.

$\checkmark 2$ Pi-Sunyer XF: Medical hazards of obesity. Ann Intern Med 1993;119:655-660.

3 Pender JR: Epidemiology of obesity in the United States. Gastroenterol Clin North Am 2005;34:1-7.

-4 Garcia HL, Orozco TR, Gonzalez BJ, Villa AR, Dalman JJ, Ortiz PG: Dermatoses in 156 obese adults. Obes Res 1999;7:299-302.

$\checkmark 5$ Sharquie KE, Al-Rawi JR, Al-Tamimi FF: The frequency of skin diseases in obese children and adult Iraqi population. Saudi Med J 2005;26:1835-1836.

-6 Hud JA Jr, Cohen JB, Wagner JM, Cruz PD Jr: Prevalence and significance of acanthosis nigricans in an adult obese population. Arch Dermatol 1992;128:941-944.

7 Yosipowitch G, DeVore A, Dawn A: Obesity and the skin: skin physiology and skin manifestations of obesity. J Am Acad Dermatol 2007;56:901-916.

8 Scheinfeld NS: Obesity and dermatology. Clin Dermatol 2004;22:303-309.

-9 Hahler B: An overview of dermatological conditions commonly associated with the obese patient. Ostomy Wound Manage 2006; 52:34-36.

10 Al-Isa AN: Obesity among Kuwait University students: an explorative study. J R Soc Health 1999;119:223-227.

-11 Al-Isa AN, Moussa MA: Factors associated with overweight and obesity among Kuwaiti kindergarten children aged 3-5 years. Nutr Health 1999;13:125-139.
12 Rotimi K: Kuwait has the highest obesity level in the world: a policy proposal to reduce prevalence. Am Public Health Assoc 133rd Annu Meet Exposition, Philadelphia, Dec 2005.

13 Birtane M, Tuna H: The evaluation of plantar pressure distribution in obese and nonobese adults. Clin Biomech 2004;19:10551059.

- 14 Araujo MB, Porto MV, Netto EM, Ursich MJ: Association of acanthosis nigricans with race and metabolic disturbances in obese women. Braz J Med Biol Res 2002;35: 59-64.

15 Mousa AM, Soliman MM, Hamza MR: Obesity and skin diseases. J Egypt Public Health Assoc 1977;52:65-74.

16 Torley D, Bellus GA, Munro CS: Genes, growth factors and acanthosis nigricans. $\mathrm{Br}$ J Dermatol 2002;147:1096-1101.

17 Barth JH, Ng LL, Wojnarowska F, Dawber RP: Acanthosis nigricans, insulin resistance and cutaneous virilism. Br J Dermatol 1988; 118:613-619.

18 Baratta M: Leptin - from a signal of adiposity to a hormonal mediator in peripheral tissues. Med Sci Monit 2002;8:282-292.

19 Yazici AC, Tursen U, Ikizoglu G, Akbay E, Tataroglu C, Cimen MY: Atypical localization of acanthosis nigricans in an obese patient with increased leptin level: is there an association? J Am Acad Dermatol 2006; 55:S55-S56.

20 Katz A, Goff D, Feldman D: Acanthosis nigricans in obese patients: presentations and implications for prevention of atherosclerotic vascular disease. Dermatol Online J 2000; $6: 1-12$.
21 Kahana M, Grossman E, Feinstein A, Ronnen M, Cohen M, Millet MS: Skin tags: a cutaneous markers for diabetes mellitus. Acta Derm Venereol 1987;67:175-177.

-22 Rasi A, Soltani-Arabshahi R, Shahbazi N: Skin tag as a cutaneous marker for impaired carbohydrate metabolism: a case-control study. Int J Dermatol 2007;46:1155-1159.

23 Yosipovitch G, Tur E, Cohen O, Rusecki Y: Skin surface $\mathrm{pH}$ in intertriginous areas in NIDDM patients: possible correlation to candidal intertrigo. Diabetes Care 1993;16: 560-563.

24 Ruutiainen K, Erkkola R, Gronroos MA, Irjala K: Influence of body mass index and age on the grade of hair growth in hirsute women of reproductive ages. Fertil Steril 1988;50: 260-265.

25 Sakai R, Matsui S, Fukushima M, Yasuda H, Miyauchi H, Miyachi Y: Prognostic factor analysis for plaque psoriasis. Dermatology 2005;211:103-106.

$\checkmark 26$ Naldi L, Chatenoud L, Linder D, Fortina AB, Peserico A, Virgili AR, Bruni PL, Ingordo V, Scocco GL, Solaroli C, Schena D, Barba A, Landro AD, Pezzarossa E, Arcangeli F, Gianni C, Betti R, Carli P, Farris A, Barabino GF, Vecchia CL: Cigarette smoking, body mass index, and stressful life events as risk factors for psoriasis: results from an Italian case-control study. J Invest Dermatol 2005; 125:61-67.

27 Johnston A, Arnadottir S, Gudjonsson JE, Aphale A, Sigmarsdottir AA, Gunnarsson SI, Steinsson JT, Elder JT, Valdimarsson H: Obesity in psoriasis: leptin and resistin as mediators of cutaneous inflammation. Br J Dermatol 2008;159:342-350. 